\title{
Editorial Review of Volume 14
}

\section{SYLVIA L. THRUPP}

A visitor to the editorial office lately remarked that this is the only journal he knows that is full of surprises. Yet our writers' concerns are for the most part familiar in some other setting to any student of society. It is the encounter with familiar problems on strange terrain that invests them with surprise, and can renew their analytical challenge.

Volume 14 has concentrated mainly on deepening discussion of questions already in the CSSH repertoire. One of these, of equal interest to historians, sociologists, and political scientists, is that of the formation of elite groups, including bureaucracies. It is treated, in the first two numbers, through solid research on the old regime in France and Russia, and in Brazil. Armstrong's presentation of career patterns among French intendants and Russian governors closely parallels the work of Pang and Seckinger on the political and administrative elite of Imperial Brazil. Both articles probe the relative effectiveness of different systems of training and recruitment in harmonizing the interests of a central regime with the emergent needs of economic development, the Brazilian study laying rather more emphasis on the economic aspects of regionalism. Gayl D. Ness's theoretical comments on a somewhat differently oriented study set in colonial Malay, in 12:2 (1970), and James W. Fesler's comparisons of French, British and American preferences among systems of field administration in 5:1 (1962), remain relevant.

Legal professions have been treated earlier in such diverse settings as nineteenth-century Philadelphia, with a side-glance at British experience, and in twentieth-century Indonesia, in 7:2 and 8:1 (1965), and in India at various periods in volumes 4,5 and 8 . Introducing the new group of articles in 14:1 on legal culture in modern India, Marc Galanter argues that many of the conventional assumptions about the normal place of law in a society are in part mere projections of the working myths of modern Western legal systems. The papers that follow cut down to the level of the para-professional, whose role, now ubiquitous in the less developed countries, is viewed for brief comparison also in Ghana.

A spirited review article in 7:1 (1964) by D. A. Low, castigating writing on Africa that relegated Africans to the background of their own history and otherwise distorted their past helped to make CSSH one of the outlets for newer types of research in that field. These fit well into the cumulative comparative study we have welcomed on such matters as intercultural borrowing, village economies, and on problems raised by different formulations of the concepts of charisma, and of populism. Volume 14 deals with all of these in African settings, and contains as well a very substantial study of African state formation, centered on the case of Buganda. By an anthro- 
pologist, Conrad P. Kottak, this plays up with convincing thoroughness the crucial role of food resources-in this case cattle and bananas-in favoring the expansion of one power structure over another. Finally, recent African political experience is the source of Leo Kuper's belief that classical Marxian revolutionary theory cannot adequately explain today's conflicts, in that continent. His 'Race, Class and Power', concisely reviewing the alternatives facing theorists of revolutionary change, is a sequel to his article in 13:1. The last number of that volume was largely devoted to a problem he sees as central, that of how people actually perceive racial differences. Kuper's ideas admirably supplement Richard Ashcraft's fresh and elegant analysis, in 14:2, of the relationships between theory, ideology and action.

The other articles in the last two numbers of this volume all offer tentative revisions of some branch or other of social theory to make it square better with their authors' research experience. Edward Hansen and his collaborators adapt patronage theory to help them argue the futility of trying to apply conventional modernization theory to the Mediterranean world. To mention only one other example, Martha E. François is the first historian to respond constructively to G. E. Swanson's sociological view of the European Reformation. Modifying his model, she moves on to propose new starting-points for generalization through further study of the variety of ways in which men could perceive the immanence of God.

From its start, $\mathrm{CSSH}$ found subscribers in over fifty countries, and in its fourteen years of life has published work from thirty of these. The national origins of many of those who write for us within the U.S.A. are also quite diverse. Indeed, we are so far from being dominated by American preoccupations that one of the editors' desires has been to draw American life more continuously into comparative perspective. Another aim, in line with our interest in the expressive and symbolic aspects of culture, is to draw more frequently on the perceptions of writers trained in the arts and in the field of comparative literature.

Readers will notice that they are getting longer issues now. This is a compensation for the fact that our publishers, bedevilled by rising costs, have regretfully had to raise our hitherto modest price. With the extra space we shall be able, in future, to run more review essays, and more debate.

Elsewhere in this volume one of our writers refers briefly to the debt that he and other Islamic scholars owe to Gustave E. von Grunebaum. The death of so great a humanist at the height of his intellectual powers, on February 27, 1972, was a shock even to those who knew him only through his books. This is not the place to speak of their richness and scope. But it is appropriate to record here that without his wise counsel and enthusiastic help as a founding editor, $\mathrm{CSSH}$ would never have come into existence. 